\title{
Supervisão de estágio em Serviço Social: significâncias e significados
}

\section{Lesliane Caputi}

Universidade Federal do Triângulo Mineiro (UFTM)

\section{Supervisão de estágio em Serviço Social: significâncias e significados}

Resumo: $\mathrm{O}$ artigo propõe reflexões acerca de textos e contextos que envolvem a supervisão de estágio em Serviço Social, considerando as significâncias e significados da supervisão de estágio, especialmente no que diz respeito às atribuições privativas do/a assistente social. Embasado no método crítico-dialético, aborda a supervisão de estágio enquanto dimensão da formação e exercício profissional, não desvinculada dos seus componentes ético-filosóficos, pedagógicos, políticos, e dos aspectos elementares para o estágio.

Palavras-Chave: Serviço Social. Supervisão de Estágio. Formação e Exercício Profissional.

\section{Supervision of Internships in Social Work: Significances and meanings}

Abstract: This article reflects on texts and contexts that involve the supervision of internships in social work, considering its significances and meanings, especially concerning attributions particular to social workers. It is based on a critical-dialectical method, and addresses the supervision of internships as a dimension of professional education and exercise, which is not separated from ethical-philosophical, pedagogical, and political components, and the basic aspects of the internship.

Keywords: Social Service. Supervision of Internships. Professional education and Practice. 


\section{Introdução}

Um dos pilares do projeto ético-político do Serviço Social é a formação profissional. Por meio do projeto de profissão, as entidades representativas (Associação Brasileira de Ensino e Pesquisa em Serviço Social/ABEPSS, Conselho Federal de Serviço Social/CFESS, Conselho Regional de Serviço Social/CRESS, Executiva Nacional de Estudantes de Serviço Social/ENESSO), reafirmam sua defesa e fortalecem sua continuidade. Esta concepção se configura como uma indispensável referência, de acordo com o CFESS (2010)1, "tendo em vista as ameaças sofridas mediante os constantes ataques da contrarreforma na educação", em que a expressão da mercantilização e da precarização da educação superior traz fortes rebatimentos na formação e no exercício profissional, sobretudo, na qualidade dos serviços prestados à população usuárias das políticas públicas.

O estágio supervisionado em Serviço Social e, com ele, o processo de supervisão, acompanha o movimento sócio histórico, teórico-metodológico e as condições éticas e políticas que envolvem a profissão, desde os seus primórdios na realidade brasileira. O debate sobre a supervisão de estágio no Serviço Social é efervescente nos tempos hodiernos, sobretudo considerando: a maturidade intelectual da categoria; a perspectiva de indissociabilidade entre formação e exercício profissional; as lutas travadas na defesa da educação de qualidade e a resistência com relação à precarização da educação superior e suas ressonâncias no Serviço Social, sobretudo, no que diz respeito à modalidade de Ensino à Distância para graduação; preocupação diante da ofensiva neoliberal; e enfim, o compromisso com a consolidação do Projeto Ético-Político da Profissão, elementos pelos quais, foi delineada em 2008, pelo CFESS, a Resolução n.533, responsável pela regulamentação da supervisão direta de estágio, e, em 2010, a Política Nacional de Estágio em Serviço Social/PNE, ABEPSS².

A supervisão de estágio, de acordo com Lewgoy (2009, p. 65) "corresponde a uma das atividades mais antigas de ensinar e aprender", e, no Serviço Social surge quando este ainda tinha caráter de vocação. A supervisão acompanha o movimento da formação e trabalho profissional e se desenvolve dialeticamente com a concepção de educação superior, alinhada à perspectiva teórico-metodológica que embasa a profissão. $\mathrm{O}$ processo de supervisão de estágio ascende um campo de reflexões e debates atrelados à formação e ao exercício profissional, entre eles: a questão da educação superior e sua relação intrínseca com o mundo do trabalho; aspectos da luta por uma outra ordem societária e a ofensiva neoliberal; e sobretudo, os elementos teórico-metodológicos, ético-políticos e técnico-operativos do Serviço Social.

O estágio desafia docentes, supervisores/as de estágio, estagiários/as, coordenadores/as e colegiados de curso, a (re)pensarem o lugar do estágio e do processo de supervisão nos projetos políticos pedagógicos de curso de graduação em Serviço Social, além das instituições de ensino superior e os espaços sócio ocupacionais do/a assistente social, refletindo sobre as condições de trabalho dos/as profissionais para a efetivação do estágio e da supervisão conforme diretrizes curriculares (DCs) (ABEPSS, 1996/2000), PNE (ABEPSS, 2010), e Resolução n.533 (CFESS,2008), além da Lei Geral de Estágio n.11788/2008.

Nos limites deste artigo, enquanto espaço de expressão de ideias sobre a supervisão de estágio, refletimos textos e contextos que envolvem a supervisão, dando-lhe significâncias e significados, especialmente, no bojo das atribuições privativas do/a assistente social e o quão ainda se faz esparsa a produção de conhecimento na profissão.

\section{Formação e exercício profissional: unidade dialética necessária para se pensar a supervisão de estágio em Serviço Social}

Remando na contracorrente da lógica da formação profissional subordinada às leis utilitárias do mercado, o projeto de formação delianeado pelo Serviço Social se dirige para a construção de alternativas e estratégias profissionais que contribuam para a defesa dos interesses da classe trabalhadora. Nesta perspectiva, "o projeto de formação profissional é a defesa da universidade pública, gratuita e de qualidade, acompanhada da denúncia dos efeitos deletérios da privatização do ensino superior" (IAMAMOTO, 2000, p. 444). Tal defesa opõe-se à redução da formação ao mero desenvolvimento da racionalidade técnico-instrumental, o que exige do estágio supervisionado e com ele a supervisão acadêmica e de campo a tarefa de possibilitar experiências que ultrapassem o atendimento exclusivo das novas demandas do mercado de trabalho, ampliando os horizontes da formação do profissional com o desenvolvimento de competências técnico-operativas, compromisso ético-político e sustentação teórico-metodológica para o desenvolvimento da capacidade de decifrar a realidade e construir propostas de trabalho criativas e efetivar direitos (LEWGOY, 2009).

Desse modo, dialeticamente, a formação e o exercício profissional constituem os pilares de sustentação do estágio supervisionado e da supervisão acadêmica e de campo. É nesta relação que o estudante percebe o cotidiano do trabalho do/a assistente social e identifica que há, na profissão, um conceito de 
trabalho transversal, e é, nesta perspectiva, que o projeto profissional se delineia. Supervisor/a e estagiário/ a precisam refletir acerca da concepção de trabalho pautada na relação de transformação homem/mulher versus natureza, que resulta no fato do/a homem/mulher se tornarem sujeitos a partir do trabalho, o que está imbricado na formação profissional. Ambos precisam, juntos, identificar as mediações do trabalho assalariado do/a assistente social no contexto universal do sistema capitalista. É preciso, então, entender o Serviço Social como profissão inserida na divisão social e técnica do trabalho, e que para tal, requer uma formação profissional generalista, crítica e de sólida sustentação teórico-metodológica, ético-política e técnico-operativa. Afinal, estágio e supervisão, como elementos inerentes da formação e exercício profissional, sofrem conjuntamente os reflexos da crise do capital, da política reducionista de direitos sociais efetuada pelo Estado, da reforma universitária, da mercantilização da educação, dos achatamentos salariais, do retrocesso ao pensamento conservador e suas sequelas desenfreadas.

No contexto marcado pela precarização da educação, especificamente a educação superior e a consequente deterioração do mundo do trabalho se constrói nossas preocupações no âmbito do Serviço Social, olhando para as mediações que envolvem a supervisão de estágio, considerando, no todo, que a história da sociedade é, até nos dias atuais, a história da luta de classes (MARX; ENGELS, 1986). Pensar o processo de supervisão coerente com o projeto ético-político requer afirmar compromisso com a concepção de luta pela efetivação da educação como instrumento de transformação da vida social, mediada por lutas e resistências aos ditames do capital, e que pode possibilitar uma educação libertadora, permanente, emancipadora e não engastada na lógica do ideário neoliberal que atravessa este momento histórico da sociedade brasileira.

A supervisão de estágio ocorre no espaço e tempo do cotidiano do estágio supervisionado na graduação em Serviço Social. É de competência e atribuição privativa dos/as assistentes sociais, conforme Lei n. 8662/1993, de Regulamentação da Profissão ${ }^{3}$, e toda a sua dinâmica se conecta a processos sócio-políticos, éticos, normativos e jurídicos da categoria, e impera os rebatimentos do contexto da educação superior, do mercado de trabalho, e de processos internos à profissão. Envolve, assim, "a complexidade, de que formação e exercício profissional são imersos em um conjunto de relações sociais, o que faz com que sua compreensão não deva se esgotar em seu sentido estrito do fazer cotidiano", mas considerá-lo (CFESS, 2014, p. 18). O processo da trajetória histórica da profissão no Brasil legou uma concepção crítico-dialética hegemônica à formação e ao exercício profissional, concepção esta, que anua o Conselho Federal de Serviço Social (CFESS/gestão 2011-2014): "incide em especial no entendimento de que o estágio, na formação profissional do assistente social, deve superar uma concepção praticista, dissociada do corpo teórico que lhe dá fundamento, rompendo com a visão voluntarista (ou ainda imediatista) do saber-fazer"' (CFESS, 2014, p. 6).

A perspectiva de superação concebe o estágio e a supervisão como indissociáveis, unidades indissolúveis. E, nesta lógica, também a indissociabilidade entre supervisão de campo e supervisão acadêmica. Desse modo, a supervisão que compõe o projeto de formação é igualmente componente de um projeto de profissão que comporta sua orientação teórica e direção ético-política, concorde com Guerra e Braga (2009, p. 534): “não pode ser compreendida

O processo de supervisão de estágio ascende um campo de reflexões e debates atrelados à formação e ao exercício profissional, entre eles: a questão da educação superior e sua relação intrínseca com o mundo do trabalho; aspectos da luta por uma outra ordem societária e a ofensiva neoliberal; e sobretudo, os elementos teóricometodológicos, ético-políticos e técnico-operativos do Serviço Social. desvinculada dos seus componentes teórico, ético e político, da compreensão do significado social do Serviço Social na sociedade brasileira, dos valores que privilegia, de um projeto profissional que se conecta (ainda que por meio de muitas mediações) a projetos de sociedade".

A supervisão apresenta uma evolução analítica, prática e política intrínseca ao processo de formação profissional, tanto que se desenvolve historicamente em consonância com os avanços e desafios postos à profissão. Nesse sentindo, não se trata apenas da construção técnica e operativa do fazer profissional, mas também da dimensão intelectiva, ética e ontológica do trabalho, considerando aquilo que é específico ao trabalho do/a assistente social (ABESS; CEDEPSS, 1997). 
A interlocução do Serviço Social com o referencial teórico critico-dialético confere à supervisão o espaço de troca de conhecimento entre os atores envolvidos, no qual todos têm conhecimento e/ou experiências para trocar, ensinar e aprender. Nesse sentido, a relação ensino-aprendizagem numa perspectiva de unidade do diverso passa a ser entendida como processo contínuo de construção de conhecimentos e saber profissional alinhado ao projeto de profissão. Para José Paulo Netto (1996) o projeto de profissão, deve ser concebido para além de um conjunto de prescrições normativas e corporativas, como atributo da profissão que busca se aproximar, com o projeto societal emancipatório. Estrutura-se na sua dimensão jurídico-normativa, com a aprovação e difusão do Código de Ética de 1993 e a Lei n. 8.662/1993 que regulamenta a profissão; na dimensão política, com a (re)organização e o fortalecimento das entidades de organização da categoria (CFESS/CRESS, ABEPSS e ENESSO) e na dimensão formativa, por meio da elaboração e implementação das DCs do Serviço Social.

Considerando o debate hegemônico da categoria, a supervisão de estágio é tratada conforme o que preconizam as Diretrizes Curriculares elaboradas pela ABEPSS ${ }^{4}$ (1996), bem como a regulamentada pelo Conselho Nacional de Educação (CNE, 2001), atreladas ao Código de Ética do Assistente Social (CFESS, 1993), Lei n.8.662/1993 (CFESS, 1993) de Regulamentação da Profissão, Lei Federal de Estágio n. 11.788/ 2008 (BRASIL, 2008), Resolução CFESS n. 533/2008 (CFESS, 2008) que Regulamenta a Supervisão Direta e a Política Nacional de Estágio em Serviço Social (ABEPSS, 2010), dentro do contexto da educação superior no país, e da realidade do exercício profissional particularizada.

Cabe dizer que o estágio supervisionado e a supervisão de campo e acadêmica devem se efetivar de forma coesa entre os últimos anos de integralização do curso (a partir de $5^{\circ}$. período), a partir do estudo de conhecimentos elementares pelo/a estudante, como: "fundamentos histórico teórico-metodológicos do Serviço Social I e II e ética profissional, pela necessidade de formação do senso crítico e conhecimentos específicos básicos da profissão" (ABEPSS, 2010, p. 29).

O processo de supervisão deve ser de acompanhamento direto e sistematizado ${ }^{5}$ e realizado em concomitância com a supervisão de campo (assistente social do campo de estágio) e a supervisão acadêmica (assistente social-docente, responsável pela disciplina de supervisão acadêmica). No entanto, essa articulação tem se apresentado historicamente desafiante. É uma relação ainda marcada pelo distanciamento entre instituição de ensino e campo de estágio, entre supervisor/a de campo e acadêmico/a, e até mesmo pela concepção de estágio e supervisão, ainda como secundários à formação e exercício profissional. Além, é claro, do contexto de precarização do trabalho e da educação que influencia o Serviço Social como um todo e, não raras vezes, da dificuldade por parte do/a assistente social com a identidade da atribuição supervisor/a de estágio (seja de campo ou acadêmico).

Supervisão de campo e acadêmica enquanto faces de uma mesma atividade curricular, dialeticamente demandam, por exemplo, respostas e reflexões próprias do arcabouço teórico-prático que constituem formação e trabalho profissional. Cujas respostas estão nas mediações construídas conjuntamente pelos seus atores: supervisores e estagiários no processo da supervisão, no espaço do fazer profissional, na análise institucional que se faz do trabalho profissional. Ambas as supervisões (de campo e acadêmica), tem suas particularidades. São momentos distintos que constituem intrinsecamente o mesmo processo, que é o estágio supervisionado. Logo, ambos/as supervisores/as devem dialogar e identificar as particularidades de suas respectivas proposições. Não desconsiderando, é claro, que a supervisão de campo tem uma dinâmica mais rápida que a supervisão acadêmica. $\mathrm{O} / \mathrm{a}$ assistente social que assume a atribuição de supervisor/ de campo, além de supervisionar o/a estagiário/a tem, por exemplo, uma fila de pessoas para fazer atendimento, tendo de cumprir (muitas vezes, hoje no processo de precarização) metas no seu trabalho profissional e tem que dar conta de refletir com o/a estudante a intervenção e encaminhamentos que ele/a fez. E, assim, à supervisão acadêmica cabe afinar com o/a estagiário/a, os elementos teórico-metodológicos, ético-políticos e técnico-operativos da profissão; afinal, é na supervisão acadêmica que os/a estagiários/a levam as angústias e dinâmicas do campo de estágio para a sala de aula (CAPUTI, 2014). O/a supervisor/a acadêmico/a tem que ser um/a professor/a com visão generalista e consistente dos elementos que constituem a formação profissional em Serviço Social, para que consiga articular os conteúdos das diversas disciplinas, dos diversos componentes curriculares e construir uma síntese do trabalho profissional do/a assistente social, para que o/a estudante compreenda aquele espaço em que ele/ a está inserido. A supervisão acadêmica tem que trazer elementos fundamentais, por exemplo, da economia política, do fetiche da mercadoria, de mais-valia, da teoria do valor trabalho, entre outros que constituem os fundamentos do trabalho profissional.

A supervisão acadêmica tal como a supervisão de campo é extremamente dinâmica. O/a supervisor/a acadêmico/a pode propor uma reflexão para a aula, e na hora, surgir outra apontada pelo/a estagiário/a, por exemplo. E partir desse apontamento, o/a supervisor/a tem que resgatar o conteúdo da disciplina de sociologia e refletir sobre o que ele/a (estagiário/a) entendeu acerca do estruturalismo, o modo como as instituições se 
organizam nesse processo, buscando refletir e fazer o/a estagiário/a entender a lógica da insuficiência de recursos articulada pela política neoliberal, sobretudo, a questão da não garantia dos direitos sociais e etc. O/a supervisor/a acadêmico/a tem que estar preparado/a para exercer a supervisão, para articular os conteúdos da formação profissional, propiciar o entendimento da relação de unidade do diverso entre teoria e prática transversal na formação e exercício profissional - ainda que seja de competência também do/a supervisor/a de campo, de quem igualmente se requer muito preparo teórico-prático.

Num todo, temos que a supervisão de estágio apresenta limites próprios das determinantes advindas da precarização do mundo do trabalho e da educação, cujas possibilidades estão intrínsecas na leitura crítica da realidade concreta e no fortalecimento da identidade profissional construída. Configura-se como dimensão educativa, formativa, pedagógica e do exercício profissional, calcada nas dimensões teórico-metodológicas, ético-política e técnico-operativa do Serviço Social num processo permanente de construção de competências aliada à dimensão política, identidade e autonomia profissional, atrelada ao perfil e ethos profissional. A supervisão demanda uma relação de unidade e de diálogo permanente entre supervisor/a de campo, supervisor/a acadêmico/a e estagiário/a e, também, a construção coletiva de uma proposta de estágio, bem como do processo de supervisão direta e sistemática. Assim, há a necessidade dos atores se conhecerem; conhecerem os respectivos planos de trabalhos, a matriz curricular e o projeto pedagógico do curso, com base nos quais terá a construção do plano de estágio.

Nas Diretrizes Curriculares (ABEPSS, 1996), dentre os vários componentes curriculares, observa-se que a supervisão de estágio é norteada por princípios, objetivos e espaços formativos que ultrapassam os aspectos técnico-pedagógicos, requerendo competências éticas, teóricas e políticas, coerentes com o projeto de profissão, conferindo à supervisão de estágio atributo indispensável no desenvolvimento da formação profissional, pressupondo supervisão sistemática ligada à atividade de estágio, recomendando que a supervisão seja desenvolvida por "professor supervisor e pelo profissional de campo, através de reflexão e do acompanhamento e sistematização com base em planos de estágio, elaborados em conjunto entre Unidade de Ensino e Unidade de Campo de Estágio, tendo como referencia a Lei. n. 8.662/1993 (Lei de Regulamentação da Profíssão) e o Código de Ética do profissional (1993)" (ABESS/CEDEPSS, 1997, p. 71). No entanto, não raras vezes, há falta de condições propícias para que o/a profissional possa realizar a supervisão de campo com qualidade. O/a profissional está sobrecarregado de atividades e demandas, não consegue tempo e até mesmo recursos financeiros para sua educação permanente, considerando os achatamentos salariais que também assolam o cotidiano do/a Assistente Social. Além disso, pode ocorrer do/a profissional optar por não exercer a supervisão de estágio. Conforme alerta a ABEPSS (2010, p. 8): "No contexto de precarização e desregulamentação do trabalho e redução dos direitos é importante destacar que a discussão do estágio supervisionado se coloca, como estratégica na defesa do projeto de formação profissional em consonância com o projeto ético político do Serviço Social”.

Na concepção de que o estágio e supervisão são elementos intrínsecos da formação e exercício profissional, consideramos a necessidade de um debate constante que seja atual e pertinente à categoria profissional na perspectiva de fortalecimento das lutas e resistências profissionais. A supervisão de estágio é momento ímpar de análise concreta de situações concretas e relevantes para se compreender as dimensões constitutivas das questões específicas que se põem no campo de estágio, como também para a instrumentalização do/a estagiário/a. Configura-se como espaço para se equacionar o significado e o lugar do instrumental técnico, para se criar e recriar possibilidades políticas para a ação profissional; para se desenvolver valores éticos, e é, sem dúvida, momento privilegiado para se superar o nível de uma racionalidade imediata que é própria da vida cotidiana, e possibilitar a construção de mediações.

\section{Considerações Finais}

O estágio supervisionado, como síntese de múltiplas determinações da formação e exercício profissional, expressa o movimento teórico-prático da profissão, e juntamente ao processo de supervisão, os desafios enfrentados pela categoria profissional. O compromisso de construir uma formação profissional de qualidade e coerente com o Projeto Ético Político do Serviço Social, e com ela, a supervisão de estágio de forma direta e sistemática na sua totalidade, requer pensar, necessariamente, o estágio para além de carga horária, mas como espaço de síntese dialética da formação e trabalho profissional, o que torna imperativo uma boa dose de utopia, pois sem esta, concordando com FRIGOTTO (2001, p. 84), "não há educação, nem futuro humano".

Dessa maneira, refletindo sobre os significados, textos e contextos da supervisão de estágio em Serviço Social, é imperativo o compromisso da categoria profissional na construção de possibilidades para seu fortalecimento, o que denota envolvimento com a educação permanente da categoria, visando qualificar o processo de supervisão e a consolidação da PNE na sua totalidade. 


\section{Referências}

ABESS. CEDEPSS. Diretrizes para o curso de Serviço Social (com base no currículo mínimo aprovado em Assembleia Geral Extraordinária de 8 de novembro e 1996). Cadernos ABESS, São Paulo, p. 58-76, 1997.

ABEPSS. Política Nacional de Estágio em Serviço Social. Brasília, 2010.

CONSELHO FEDERAL DE SERVIÇO SOCIAL/CFESS. Código de Ética do Assistente Social de 1993. Lei n. 8.662, de 07 de junho de 1993, dispõe sobre a Regulamentação da Profissão. Disponível em: http://www.cfess.org.br/js/library/pdfjs/web/viewer.html?pdf=/ arquivos/CEP_CFESS-SITE.pdf. Acesso em: 20 de jan. 2016.

Resolução CFESS n. 533. De 29 de setembro de 2008 - Regulamenta a Supervisão Direta de Estágio no Serviço Social. Disponível em: http://www.cfess.org.br/js/library/pdfjs/web/viewer.html?pdf=/arquivos/CEP_CFESS-SITE.pdf. Acesso em: 8 mar. 2016.

Sobre a incompatibilidade entre graduação á distancia e Serviço Social. 2010.

. Meia formação não garante um direito: o que você precisa saber sobre a supervisão direta de estágio em Serviço Social. Brasília, 2012. Disponível em: http://www.cfess.org.br/arquivos/BROCHURACFESS_ESTAGIO-SUPERVISIONADO.pdf. Acesso em: 8 Mar. 2014.

CAPUTI, L. Supervisão de Estágio em Serviço Social: tempos de mundialização do capital- desafios cotidianos e (re)significados!. Tese de Doutorado em Serviço Social. UNESP, Franca/SP, 2014. Disponível em http://www.franca.unesp.br/Home/Pos-graduacao/ ServicoSocial/lesliane-caputi-versao-final_salva-cdroom.pdf. Acesso em: 8 Mar. 2014.

FRIGOTTO, G. Educação e trabalho: bases para debater a educação profissional emancipadora. Perspectiva, Florianópolis, p. 71-87, jan./jun. 2001.

GUERRA, Y.A.D.; BRAGA, M.E. Supervisão em Serviço Social. In: CFESS. ABEPSS. (Org.). Serviço Social: direitos sociais e competências profissionais. Brasília, DF:2009.

IAMAMOTO, M.V. O Serviço Social na contemporaneidade: trabalho e formação profissional. São Paulo: Cortez, 2000.

LEWGOY, A.M.B. Supervisão de estágio em Serviço Social: desafios para a formação e exercício profissional. São Paulo: Cortez, 2009. MARX, K. ; ENGELS, F. A ideologia Alemã: I - Feuerbach. Trad. José Carlos Bruni e Marco Aurélio Nogueira. São Paulo: Hucitec, 1986.

NETTO, J.P. Transformações societárias e Serviço Social: notas para uma análise prospectiva da profissão no Brasil. Serviço Social \& Sociedade, São Paulo, ano 17, n. 50, p. 87-132, abr. 1996.

\section{Notas}

1 Órgão normativo de grau superior da profissão. Tem por objetivo disciplinar e defender o exercício da profissão de assistente social em todo território nacional.

2 APolítica Nacional de Estágio em Serviço Social foi elaborada por um grupo de trabalho(GT) daABEPSS (gestão 2009-2010), a partir de amplas discussões com a categoria e tem expressão de construção coletiva.

3 Atualizada em 2012.

4 Associação Brasileira de Ensino e Pesquisa em Serviço Social(ABEPSS) é portadora de natureza acadêmico-científica, tem a tarefa de instituir e coordenar a direção política da formação em intrínseca relação com o exercício profissional e com a organização política dos assistentes sociais.

5 Sobre a supervisão direta de Estágio recomendamos ver a resolução n. 533/2008 elaborada pelo CFESS e disponível no site deste Conselho.

\section{Lesliane Caputi}

lesliane@hotmail.com

Doutorado em Serviço Social pela Universidade Estadual Paulista (UNESP)

Professora de Serviço Social da Universidade Federal do Triângulo Mineiro (UFTM)

\section{UFTM}

Avenida Getúlio Guaritá, n. 159. Bairro Abadia.

Uberaba - Minas Gerais - Brasil

CEP: $38.025-440$ 